\title{
Anxiety Disorders in Children and Adolescents with Autistic Spectrum Disorders: A Meta-Analysis
}

\author{
Francisca J. A. van Steensel • Susan M. Bögels • \\ Sean Perrin
}

Published online: 7 July 2011

(c) The Author(s) 2011. This article is published with open access at Springerlink.com

\begin{abstract}
There is considerable evidence that children and adolescents with autistic spectrum disorders (ASD) are at increased risk of anxiety and anxiety disorders. However, it is less clear which of the specific DSM-IV anxiety disorders occur most in this population. The present study used meta-analytic techniques to help clarify this issue. A systematic review of the literature identified 31 studies involving 2,121 young people (aged $<18$ years) with ASD, and where the presence of anxiety disorder was assessed using standardized questionnaires or diagnostic interviews. Across studies, $39.6 \%$ of young people with ASD had at least one comorbid DSM-IV anxiety disorder, the most frequent being specific phobia (29.8\%) followed by OCD $(17.4 \%)$ and social anxiety disorder (16.6\%). Associations were found between the specific anxiety disorders and ASD subtype, age, IQ, and assessment method (questionnaire versus interview). Implications for the identification and treatment of anxiety in young people with ASD are discussed.
\end{abstract}

Keywords Autism $\cdot$ Anxiety $\cdot$ Meta-analysis $\cdot$ Children · Adolescents

F. J. A. van Steensel (ه) · S. M. Bögels

Research Institute of Child Development and Education,

University of Amsterdam, Nieuwe Prinsengracht,

1301018 VZ Amsterdam, The Netherlands

e-mail: F.J.A.vanSteensel@uva.nl

S. M. Bögels

e-mail: S.M.Bogels@uva.nl

S. Perrin

Biomedical Research Centre, King's College London/Institute of Psychiatry (PO77), 16 DeCrespigny Park, London SE5 8AF, UK

e-mail: Sean.Perrin@kcl.ac.uk

\section{Introduction}

Autistic disorder, Asperger's syndrome and pervasive developmental disorder not otherwise specified (PDDNOS) are characterized by varying degrees of impairment in communication and reciprocal social interaction as well as stereotyped interests and behaviors (American Psychiatric Association 2001). In addition to these core features of the autistic spectrum disorders (ASD), the Diagnostic and Statistical Manual of Mental Disorders (DSM-IV-TR, APA 2001) identifies a range of associated difficulties including cognitive and attentional deficits, behavioral symptoms, disturbances of mood, and a lack of fear to real dangers and/ or excessive fearfulness in response to harmless objects. Indeed anxiety is viewed as sufficiently inherent to ASD that additional diagnoses of certain conditions are required "to be not better accounted for by the ASD itself" (i.e., separation anxiety disorder, social anxiety disorder, and generalized anxiety disorder). Interestingly, no such requirements exist for obsessive-compulsive disorder, specific phobia, panic disorder, or agoraphobia despite possible phenomenological overlap between the core features of these conditions and the associated features of ASD. However, whether or not comorbid symptoms of anxiety may be seen as part of the broader ASD-phenotype, such comorbidity contributes to functional impairment over and above the functional deficits of ASD with important implications for treatment and care of the young person (Matson and Nebel-Schwalm 2007). In fact, several studies have already been conducted that examined the effect of cognitive behavioral therapy (CBT) for the treatment of anxiety disorders in children with ASD and found promising results (e.g., Sofronoff et al. 2005; Chalfant et al. 2007; Reaven et al. 2009). However, within this light, it is important to establish an estimate of the prevalence of 
anxiety disorders in children with ASD and to explore the factors associated with these prevalence rates.

Several investigations of the prevalence of anxiety disorders in young people with ASD have been conducted (e.g., Leyfer et al. 2006; Simonoff et al. 2008). White et al. (2009) undertook a systematic review of the literature and identified eleven studies involving 1,353 young people (aged 6-18 years) with ASD where rates of anxiety were reported based on observation, interview, or questionnaires. Significant heterogeneity was found across studies with rates of clinically significant anxiety ranging between $11 \%$ and $84 \%$. In addition, only two studies (De Bruin et al. 2007; Simonoff et al. 2008) specifically reported rates for anxiety disorders (55 and 42\%, respectively) based on a structured diagnostic interview. To date, only one other systematic review of evidence for anxiety in children and adolescents with ASD has been undertaken. MacNeil et al. (2009) identified 13 studies (largely overlapping with those selected by White et al. 2009) where standardized measure of anxiety were administered. Again, rates for specific anxiety disorders were not reported, and there was equally large variability across studies.

Since the publications of White et al. (2009) and MacNeil et al. (2009), ten additional studies have been published where anxiety disorders were formally assessed. The primary aim of the present study was to (meta-analytically) estimate the prevalence of each specific anxiety disorder in children and adolescents with ASD by systematically reviewing all available studies reporting on anxiety disorders in youth with ASD. In addition, as previous reviews suggest that the rates of anxiety in this population may vary as a function of age, IQ, assessment method (interview versus questionnaire), informant (parent versus child), and ASD subtype (MacNeil et al. 2009; White et al. 2009), we explore the extent to which these factors "moderate" reported rates of anxiety. To our knowledge, this is the first meta-analysis of anxiety disorders in young people with ASD and the first to evaluate factors influencing the observed heterogeneity for rates of anxiety reported in the literature.

\section{Method}

\section{Literature Search}

A systematic search of computerized databases (PsyInfo, Pubmed, Web of Science, ERIC) was undertaken using the words "Autism," “Asperger," "Pervasive Development Disorder," and "PDD" in various combinations with the words "anxiety," "anxiety disorder," "anxious," "comorbid disorder," "comorbidity," "psychiatric disorder," and "psychological disorder." The abstracts were reviewed by the first author for relevance. Abstracts were considered relevant if they described their sample as having ASD and if they reported an anxiety measure. Next, the reference sections for data-based papers not found by the computer search were checked. This first search generated 86 studies including data-based studies, review papers and published presentation/poster abstracts.

\section{Selection of Studies}

To be entered into the meta-analyses, the studies had to meet the following inclusion criteria: (1) studies had to report on children with an ASD diagnosis; (2) the study was data-based and not a review of the literature; (3) the study reported the number of subjects with a DSM-IV anxiety disorder and/or the number of subjects falling above clinical cutoff for anxiety on a standardized measure of anxiety; and (4) the mean age of the sample had to be less than 18 years. From the 86 studies identified by the initial search, a total of 31 were found to meet all four inclusion criteria (see Table 1). Only two studies provided data on post-traumatic stress disorder, and these are not listed in the table. De Bruin et al. (2007) found no cases of post-traumatic stress disorder in their sample of 94 children with ASD, while Mehtar and Mukaddes (2011) found $17.4 \%$ of 69 children with ASD to be suffering from post-traumatic stress disorder.

One study (Wozniak et al. 1997) reported the percentage of participants with two or more anxiety disorders. A request for further information was made to the author, but it was no longer possible for them to provide the percentage of at least one anxiety disorder. The study was retained in the meta-analysis, and the rate for multiple anxiety disorders reported in the paper was entered into the metaanalyses as if reflected a percentage of at least one comorbid anxiety disorder. Also, the sample assessed by Gadow et al. (2004) was included in a later study by the same group but with additional subjects and with different anxiety disorders (Gadow et al. 2005). As both studies reported rates for social anxiety disorder, generalized anxiety disorder, and separation anxiety disorder, only data from Gadow et al. (2005) for these conditions were used in the meta-analysis. In the case of obsessive-compulsive disorder and specific phobia, data from Gadow et al. (2004) were used because the data of those anxiety subtypes were not reported in Gadow et al. (2005).

After contacting the author, data from one presentation abstract (Herguner and Motavalli 2009) were found to display considerable overlap with the data from the published article of Mukaddes et al. (2010), and this abstract was therefore excluded. The poster presentation of Loggins et al. (2010) was included in the meta-analysis. Besides the two abstracts mentioned above, we did not find other abstracts from presentations or posters that reported prevalence rates of anxiety in children with ASD. 


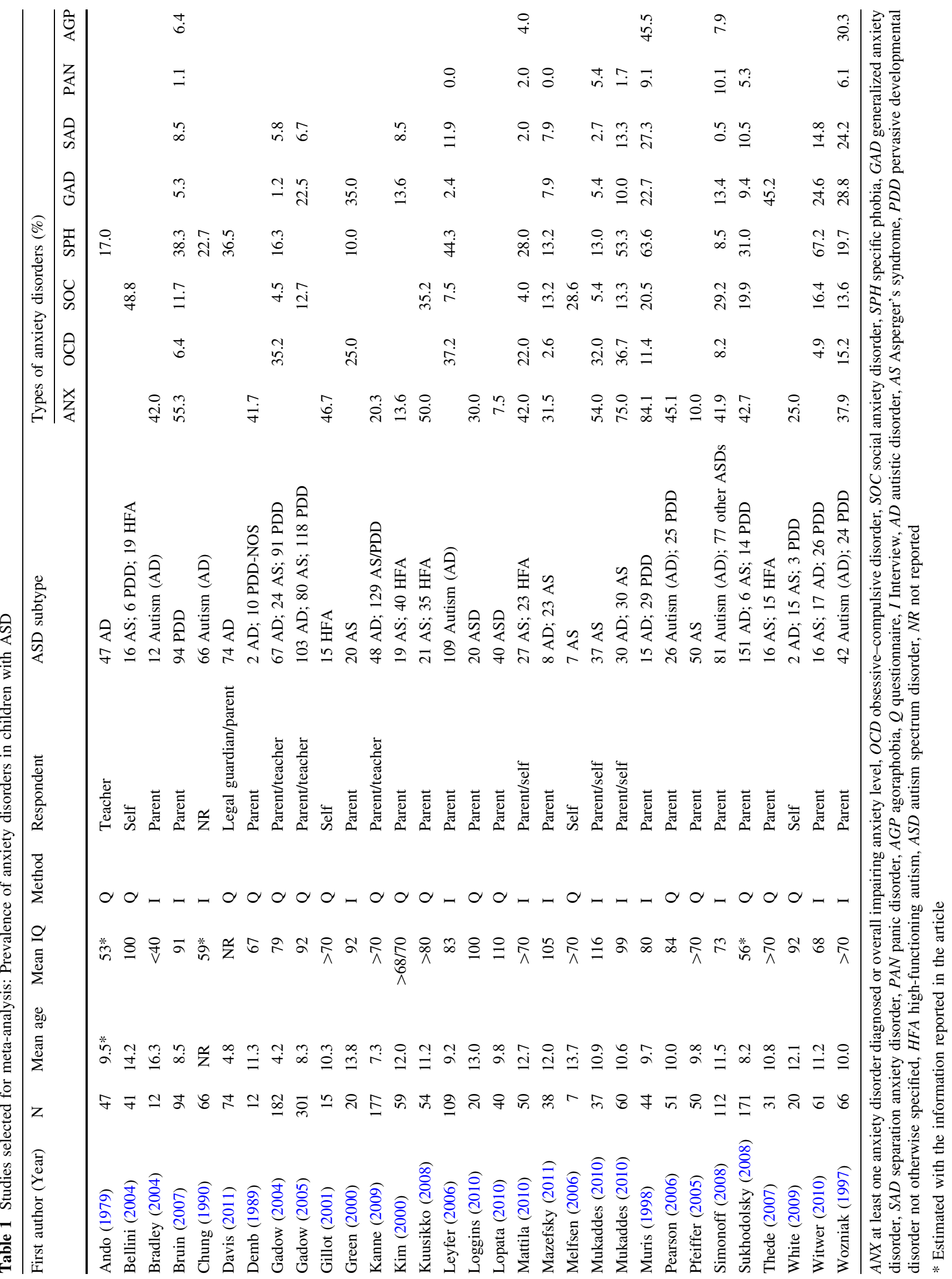


Assessment of ASD in the Selected Studies

No restrictions were made for inclusion or exclusion of studies in the meta-analysis concerning the way that ASD diagnosis was established. The most common standardized measures, however, that were used to confirm ASD diagnosis were the Autism Diagnostic Interview-Revised (ADI-R; Lord et al. 1994) and the Autism Diagnostic Observation Schedule-Generic (ADOS-G; Lord et al. 2000).

The ADI-R is a semi-structured interview with the caregiver(s) as informant(s) of a child's behavior and development. The behavioral items are grouped into three domains: (1) reciprocal social interaction, (2) communication, and (3) restricted and repetitive behaviors (Lord et al. 1994). An algorithm is provided to establish a diagnosis of autism (i.e., all scores need to exceed cutoffs of all categories). Reliability and validity is supported by the study of Lord et al. (1994). The ADOS-G is a semi-structured assessment to observe behavior of children who are suspected to have autism (Lord et al. 2000). The assessment contains four modules, and for each module, separate diagnostic algorithms are provided. Classification is made based on scores that exceed cutoffs in two domains: social behavior and communication (Lord et al. 2000). The interrater reliability, internal consistency, and test-retest reliability as well as diagnostic validity of the ADOS-G were found excellent (Lord et al. 2000).

Of the 31 selected studies, 14 studies (45.2\%) used either the ADI-R and/or the ADOS to confirm ASD diagnosis (see Table 2). In addition, five studies (16.1\%) used a second rater to either confirm ASD diagnosis or to establish inter-rater agreement of ASD diagnosis. The minority of the selected studies $(38.7 \%)$ did not use the ADI-R or ADOS nor a second rater to confirm ASD diagnosis. However, inspection of previous case records and/or interviews including developmental history was commonly used to verify ASD diagnosis in those studies.

\section{Assessment of Anxiety in the Selected Studies}

For studies to be included in the meta-analysis, anxiety had to be measured either by a (semi-) structured interview that assesses anxiety disorders or by a questionnaire that provided cutoff scores for an indication whether anxiety levels were clinically relevant. An overview of the used instruments to assess anxiety in children with ASD is displayed in Table 2. The rationale for aggregating studies that assess anxiety by diagnostic interviews and studies that used screening cutoffs of questionnaires was the following: (1) screening for anxiety disorders with questionnaires has predictive value at least in typically developing children (e.g., Simon and Bögels 2009), (2) questionnaires seem to have the ability to discriminate between anxiety-disordered and non-anxiety-disordered children in typically developing populations with good sensitivity and specificity (e.g., Beidel et al. 1996; Nauta et al. 2004; Bodden et al. 2009), and (3) the sample size of the meta-analysis was too small to run analyses separately for interviews and questionnaires. However, to overcome this latter issue, we added type of measurement method (interview versus questionnaire) as a moderator to the analyses.

Of the selected studies, 13 studies (41.9\%) used interviews to assess anxiety and 18 studies $(58.1 \%)$ used questionnaires. Only a few studies (Leyfer et al. 2006; Davis et al. 2011; Mazefsky et al. 2011) have used an instrument specifically developed for the ASD population. The instruments used in those studies were (1) the Autism Comorbidity Interview-Present and Lifetime Version (ACI-PL), which is a modified version of the Kiddie Schedule for Affective Disorders and Schizophrenia (K-SADS; Ambrosini 2000) and was used in the study of Leyfer et al. (2006) and Mazefsky et al. (2011), and (2) the questionnaires used by Davis et al. (2011), namely the Baby and Infant Screen for Children with aUtIsm TraitsPart 2 (BISCUIT-Part 2; Matson et al. 2007) and the Autism Spectrum Disorders-Comorbidity for Children (ASD-CC; Matson and González, 2007). In addition, some authors made specific adaptations to control for possible confounding overlap between ASD and anxiety by excluding several items (Sukhodolsky et al. 2008; Kuusikko et al. 2008) or training interviewers to distinguish anxiety from ASD (Simonoff et al. 2008). However, most authors did not make any adaptations to either the interview or the questionnaire used to assess anxiety in ASD. Other instruments that were used to assess anxiety in children with ASD, and which are also commonly used to assess anxiety (or psychopathology in general) in typically developing children, include the Diagnostic Interview Schedule for Children (DISC; Shaffer et al. 1996), the Kiddie Schedule for Affective Disorders and Schizophrenia (K-SADS; Ambrosini 2000), the Child Behavior CheckList (CBCL; Achenbach 1991), the Spence Children's Anxiety Scale (SCAS; Spence 1997), and the Social Phobia and Anxiety Inventory for Children (SPAI-C; Beidel et al. 1998).

\section{Coding}

The prevalence of anxiety disorders in general included studies that reported a percentage of subjects that met criteria for at least one anxiety disorder or studies that reported a percentage of subjects meeting clinical cutoff for anxiety in general. Each study was reviewed, and we calculated the percentage of children with ASD for the ASD subcategories as described in the DSM-IV-TR (APA 2001), namely subjects with (1) autistic disorder, (2) Asperger's syndrome, and (3) PDD-NOS. Studies that reported 
Table 2 Assessment of ASD and anxiety in the selected studies

\begin{tabular}{|c|c|c|}
\hline First author (Year) & Assessment of anxiety with & ASD diagnosis obtained/confirmed by \\
\hline Ando (1979) & Maladaptive behavior scale & Child psychiatrists \\
\hline Bellini (2004) & Social Anxiety Scale for Adolescents (SAS-A) & Qualified mental health professionals \\
\hline Bradley (2004) & $\begin{array}{l}\text { Diagnostic Assessment of the Severely Handicapped-2nd version } \\
\text { (DASH-II) }\end{array}$ & ADI-R \\
\hline Bruin (2007) & Diagnostic Interview Schedule for Children (DISC)—Parent version & ADOS \\
\hline Chung (1990) & Semi-structured interview of problem behaviors & First and/or second author \\
\hline Davis (2011) & $\begin{array}{l}\text { Baby and Infant Screen for Children with aUtIsm Traits-Part } 2 \\
\text { (BISCUIT-2); Autism Spectrum Disorders-Comorbidity for } \\
\text { Children (ASD-CC) }\end{array}$ & $\begin{array}{l}\text { Clinical psychologists (inter-rater } \\
\text { agreement was examined) }\end{array}$ \\
\hline Demb (1989) & Personality Inventory for Children (PIC) & $\begin{array}{l}\text { A true/false checklist that examined } \\
\text { DSM-III criteria for ASD }\end{array}$ \\
\hline Gadow (2004) & Early child inventory (ECI-4) & $\begin{array}{l}\text { Clinicians (inter-rater agreement was } \\
\text { examined) }\end{array}$ \\
\hline Gadow (2005) & Child Symptom Inventory (CSI-4) & $\begin{array}{l}\text { Clinicians (inter-rater agreement was } \\
\text { examined) }\end{array}$ \\
\hline Gillot (2001) & Spence Children's Anxiety Scale (SCAS) & Communication clinic in a local hospital \\
\hline Green (2000) & Isle of Wight Semi-structured Informant and Child Interviews & ADI-R and ADOS \\
\hline Kanne (2009) & Child Behavior CheckList (CBCL); Teacher Report Form (TRF) & ADI-R and ADOS \\
\hline Kim (2000) & $\begin{array}{l}\text { Revised questionnaire of the Ontario Child Health Study (OCHS-R) } \\
\text { (revision of CBCL) }\end{array}$ & ADI-R \\
\hline Kuusikko (2008) & $\begin{array}{l}\text { Social Phobia and Anxiety Inventory (SPAI); Social Anxiety Scale for } \\
\text { Children-revised (SASC-R); Child Behavior CheckList (CBCL) }\end{array}$ & ADI-R and ADOS \\
\hline Leyfer (2006) & $\begin{array}{l}\text { Autism Comorbidity Interview-Present and Lifetime Version (ACI- } \\
\text { PL) }\end{array}$ & ADI-R and ADOS \\
\hline Loggins (2010) & Behavioral Assessment System for Children-2 (BASC-2) & Not reported \\
\hline Lopata (2010) & Behavioral Assessment System for Children-2 (BASC-2) & ADI-R \\
\hline Mattila (2010) & $\begin{array}{l}\text { Schedule for Affective Disorders and Schizophrenia for School-Age } \\
\text { Children (K-SADS) }\end{array}$ & $\begin{array}{l}\text { ADI-R, ADOS, and Autism Spectrum } \\
\text { Screening Questionnaire (ASSQ) }\end{array}$ \\
\hline Mazefsky (2011) & $\begin{array}{l}\text { Autism Comorbidity Interview-Present and Lifetime Version (ACI- } \\
\text { PL) }\end{array}$ & ADI-R and ADOS \\
\hline Melfsen (2006) & Social Phobia and Anxiety Inventory for Children (SPAI-C) & $\begin{array}{l}\text { Two psychiatrists (both had to confirm } \\
\text { diagnosis of ASD) }\end{array}$ \\
\hline Mukaddes (2010) & $\begin{array}{l}\text { Schedule for Affective Disorders and Schizophrenia for School-Age } \\
\text { Children (K-SADS) }\end{array}$ & $\begin{array}{l}\text { A detailed developmental history of all } \\
\text { participants }\end{array}$ \\
\hline Mukaddes (2010) & $\begin{array}{l}\text { Schedule for Affective Disorders and Schizophrenia for School-Age } \\
\text { Children (K-SADS) }\end{array}$ & $\begin{array}{l}\text { Consensus of ASD diagnosis by at least } \\
\text { two child psychiatrists }\end{array}$ \\
\hline Muris (1998) & Diagnostic Interview Schedule for Children (DISC)—Parent version & A multi-disciplinary team \\
\hline Pearson (2006) & Personality Inventory for Children—Revised (PIC-R) & $\begin{array}{l}\text { Clinical interview (and ADI-R in } 20 \% \\
\text { and ADOS in } 3 \text { subjects) }\end{array}$ \\
\hline Pfeiffer (2005) & $\begin{array}{l}\text { Revised Children's Manifest Anxiety Scale Adapted Parent's Version } \\
\text { (RCMAS) }\end{array}$ & Medical doctor or psychologist \\
\hline Simonoff (2008) & $\begin{array}{l}\text { Child and Adolescent Psychiatric Assessment (CAPA) - parent } \\
\text { version }\end{array}$ & ADI-R and ADOS \\
\hline Sukhodolsky (2008) & Child and Adolescent Symptom Inventory (CASI) & ADI-R \\
\hline Thede (2007) & $\begin{array}{l}\text { Coolidge Personality and Neuropsychological Inventory for Children } \\
\text { (CPNI) }\end{array}$ & $\begin{array}{l}\text { Clinician and a } 44 \text {-item survey developed } \\
\text { by the authors }\end{array}$ \\
\hline White (2009) & Multidimensional Anxiety Scale for Children (MASC) & ADOS \\
\hline Witwer (2010) & $\begin{array}{l}\text { Children's Interview for Psychiatric Symptoms-Parent Version } \\
\text { (P-ChIPS) }\end{array}$ & ADI-R \\
\hline Wozniak (1997) & $\begin{array}{l}\text { Schedule for Affective Disorders and Schizophrenia for School-Age } \\
\text { Children (K-SADS) }\end{array}$ & Psychiatrist \\
\hline
\end{tabular}


children to have "autism" were included in the category of children diagnosed with autistic disorder. Next, the prevalence rates (percentages) for anxiety in general and the specific anxiety disorders (obsessive-compulsive disorder, separation anxiety disorder, social anxiety disorder, generalized anxiety disorder, panic disorder, and agoraphobia) were calculated. These percentages were then transformed into proportions by dividing by 100 . When multiple informants were used (e.g., rates of anxiety were reported separately for the child, parent, and/or teacher), a weighted arithmetic average (based on the number of each informant) of these rates was entered into the meta-analyses. In addition, the mean age, mean IQ, measurement method (questionnaire or interview), and informant (parent versus child report) were recorded from each study. Too little variance was found for informant (i.e., studies were heavily dominated by parent reports), and this variable was dropped from all further analyses. The first author coded all studies and then a second independent coder (with a Master of Science in social studies) coded the same studies. Interrater agreement was excellent: all kappa and interclass coefficients were above .90. Any disagreements between coders were discussed until consensus was reached.

\section{Normality, Outliers, and Publication Bias}

When aggregating effect sizes across studies, it is important to take account of any departure from normality for the resulting distribution of effects, to deal with statistical outliers, and account for the general problem of publication bias (Lipsey and Wilson 2000). The Kolmogorov-Smirnov test was used to test for the normality of distributions for each anxiety disorder separately, and no violations were found. To test for statistical outliers, all proportions of anxiety disorder subtypes were transformed into standardized $Z$ scores. When the standardized $Z$ score falls outside the confidence interval bounded by -3.3 and +3.3 , then the observation is possibly an outlier (Tabachnick and Fidell 2001). No statistical outliers for anxiety in general or for any of the specific anxiety disorders were identified using this method.

Publication bias refers to the observation that studies with (large) significant results are more likely to be published than those with non-significant or small effects. Publication bias is typically assessed via visual inspection of funnel plots (Munafò et al. 2004), tests of funnel plot asymmetry (Egger et al. 1997), or rank correlation methods (Begg and Mazumdar 1994). The validity of these methods, however, decreases when the number of studies under investigation is small (Rothstein et al. 1996). In addition, heterogeneity in the aggregated dependent variables (i.e., rates of the specific anxiety disorders) may lead to funnel plot asymmetry and false positives for statistical tests assessing asymmetry (Sterne et al. 2000). We assumed that publication was largely unrelated to the rate of anxiety disorders reported in the individual studies as no variable was manipulated to achieve a specific rate and a null result is also of theoretical value in this population (i.e., the findings are purely descriptive and were not tested to be significant or not). Nevertheless, we examined publication bias for the 20 studies that reported the prevalence of anxiety in general by statistically testing for funnel plot asymmetry with the rank order correlation coefficient, the Egger's regression method, and by adding the standard error as a moderator to the random effect model. None of these methods for detecting publication bias reached statistical significance $(r=.068, p=.776 ; t=1.407, p=.176$; $\beta=.147, p=.559)$.

\section{Results}

The first set of meta-analyses aimed to establish the mean effect size (proportions) for anxiety in general and each of the anxiety disorders separately (obsessive-compulsive disorder, separation anxiety disorder, generalized anxiety disorder, specific phobia, social anxiety disorder, panic disorder, and agoraphobia) in the absence of any "moderators." The SPSS macros from Lipsey and Wilson were used for analyses, and both fixed and random effect models were computed for each separate meta-analysis to examine whether the selected sample of studies contained heterogeneity. Tests for homogeneity were conducted with $\mathrm{Q}$ statistics and tested at $\alpha=.05$.

The second set of meta-analyses tested whether the rates of anxiety varied systematically across studies owing to the proportion of subjects in each study with autistic disorder, Asperger's syndrome, and PDD-NOS; mean age; mean IQ; and whether questionnaires or interviews were used to assess anxiety. Moderator analyses were carried out separately for studies reporting rates for anxiety in general, specific phobia, social anxiety disorder, generalized anxiety disorder, separation anxiety disorder, obsessivecompulsive disorder, and panic disorder. For agoraphobia, the number of studies was too small $(k=5)$ to conduct moderator analysis reliably. Moderator variables were entered separately in all analyses. If several moderators were significant, those moderators were included simultaneously in the model to test for the robustness of their effect.

\section{Results of Meta-Analyses}

Results of the first set of meta-analyses (without moderators) are presented in Table 3. The column titled "Prevalence" includes the percentage (estimated) of subjects across studies who were diagnosed with at least one anxiety disorder or have impairing levels of anxiety (ANX) 
Table 3 Results of the metaanalyses for the prevalence of anxiety disorders in children with ASD
$* p<.01$

$k$ number of studies, $C I$ confidence interval, $A N X$ at least one anxiety disorder diagnosed or impairing anxiety level above clinical cutoff, $O C D$ obsessive-compulsive disorder, $S O C$ social anxiety disorder, $S P H$ specific phobia, $G A D$ generalized anxiety disorder, $S A D$ separation anxiety disorder, $P A N$ panic disorder, $A G P$ agoraphobia

\begin{tabular}{|c|c|c|c|c|c|c|}
\hline Meta-analysis & $k$ & Prevalence $(\%)$ & CI $(95 \%)$ & $Z$ & $Q$ & $p$ \\
\hline \multicolumn{7}{|l|}{ ANX } \\
\hline Fixed & 20 & 34.8 & $32.3-37.2$ & 28.032 & & $<.001 *$ \\
\hline Random & 20 & 39.6 & $29.7-49.6$ & 7.798 & & $<.001 *$ \\
\hline Homogeneity test & & & & & 293.662 & $<.001 *$ \\
\hline \multicolumn{7}{|l|}{ OCD } \\
\hline Fixed & 12 & 12.5 & $10.5-14.6$ & 11.916 & & $<.001 *$ \\
\hline Random & 12 & 17.4 & $10.3-24.6$ & 4.772 & & $<.001 *$ \\
\hline Homogeneity test & & & & & 120.366 & $<.001 *$ \\
\hline \multicolumn{7}{|l|}{ SOC } \\
\hline Fixed & 15 & 13.4 & $11.5-15.2$ & 14.261 & & $<.001 *$ \\
\hline Random & 15 & 16.6 & $12.0-21.3$ & 7.056 & & $<.001 *$ \\
\hline Homogeneity test & & & & & 74.403 & $<.001 *$ \\
\hline \multicolumn{7}{|l|}{ SPH } \\
\hline Fixed & 16 & 24.6 & $22.3-26.8$ & 21.538 & & $<.001 *$ \\
\hline Random & 16 & 29.8 & $21.5-38.1$ & 7.028 & & $<.001 *$ \\
\hline Homogeneity test & & & & & 194.823 & $<.001 *$ \\
\hline \multicolumn{7}{|l|}{ GAD } \\
\hline Fixed & 14 & 9.8 & $8.2-11.5$ & 11.944 & & $<.001 *$ \\
\hline Random & 14 & 15.4 & $10.2-20.5$ & 5.873 & & $<.001 *$ \\
\hline Homogeneity test & & & & & 105.075 & $<.001 *$ \\
\hline \multicolumn{7}{|l|}{ SAD } \\
\hline Fixed & 13 & 3.5 & $2.5-4.5$ & 6.807 & & $<.001 *$ \\
\hline Random & 13 & 9.0 & $5.5-12.5$ & 5.021 & & $<.001 *$ \\
\hline Homogeneity test & & & & & 85.022 & $<.001 *$ \\
\hline \multicolumn{7}{|l|}{ PAN } \\
\hline Fixed & 10 & 0.2 & $-0.1-0.5$ & 1.074 & & .283 \\
\hline Random & 10 & 1.8 & $0.6-3.0$ & 2.979 & & $<.003 *$ \\
\hline Homogeneity test & & & & & 34.861 & $<.001 *$ \\
\hline \multicolumn{7}{|l|}{ AGP } \\
\hline Fixed & 5 & 9.2 & $6.4-12.0$ & 6.422 & & $<.001 *$ \\
\hline Random & 5 & 16.6 & $6.7-26.5$ & 3.290 & & $<.002 *$ \\
\hline Homogeneity test & & & & & 42.305 & $<.001 *$ \\
\hline
\end{tabular}

and each anxiety disorder: obsessive-compulsive disorder, social anxiety disorder, specific phobia, generalized anxiety disorder, separation anxiety disorder, panic disorder, and agoraphobia. The significance values associated with the fixed and random models indicate whether the (estimated) prevalence is significantly different from zero. All homogeneity analyses yielded significant results, indicating significant variability in rates of disorders across studies.

\section{Moderator Analyses}

Results of the moderator analyses are presented in Table 4. On the left-hand side of the table are listed anxiety in general (ANX), which refers to any anxiety disorder (diagnostic interview) or clinically elevated anxiety (questionnaire), and each of the specific anxiety disorders (specific phobia, obsessive-compulsive disorder, social anxiety disorder, generalized anxiety disorder, separation anxiety disorder, and panic disorder), and on the right, the results for the different moderators. The first column (Dir) indicates whether the moderator is associated with higher $(+)$ or lower $(-)$ rates of anxiety, followed by the coefficients for each moderator variable $(\beta)$, an indication whether it was significant in the random (RM) or fixed effect (FM) model, and the corresponding p value. Heterogeneity remained significant in all fixed effect models. We will briefly give a summary of the results for each moderator.

\section{Method}

Method of measurement (questionnaire versus interview) was found significant for anxiety in general (ANX), and the specific anxiety disorders (social anxiety disorder, generalized anxiety disorder, and separation anxiety disorder). 
The use of interviews was associated with higher prevalence rates of anxiety in general, while for social anxiety disorder, the use of questionnaires was associated with higher prevalence rates. In addition, studies that used questionnaires to assess generalized anxiety disorder and separation anxiety disorder reported higher prevalence rates of those disorders compared with studies that used interviews. The moderator "method" remained significant when other moderators were included simultaneously, except for separation anxiety disorder. In this case, the method was no longer found significant when mean age was entered simultaneously.

\section{Mean Age}

The moderator mean age was found significant for anxiety in general (ANX), and for several anxiety disorders: obsessive-compulsive disorder, generalized anxiety disorder, and separation anxiety disorder. For anxiety in general and generalized anxiety disorder, it was found that studies that reported a higher mean age also reported higher prevalence rates. However, for obsessive-compulsive disorder and separation anxiety disorder, higher prevalence rates were associated with studies that reported a lower mean age. In all these models, the moderator "mean age" remained significant when multiple moderators were included.

\section{$I Q$}

IQ was found to have a significant moderating effect for rates of anxiety in general (ANX) and for the following anxiety disorders: obsessive-compulsive disorder, social anxiety disorder, and separation anxiety disorder. Studies that reported a lower mean IQ were associated with higher prevalence rates of anxiety in general and social anxiety disorder. In contrast, studies that reported a higher mean IQ were associated with higher prevalence rates of obsessivecompulsive disorder and separation anxiety disorder. For anxiety in general (ANX) and social anxiety disorder, this moderator remained significant when multiple moderators were included in the model; however, for obsessive-compulsive disorder and separation anxiety disorder, the moderating effect of IQ was no longer found significant when other moderators were included simultaneously.

\section{ASD Subtype}

For anxiety in general (ANX), it was found that the moderators "AS" (proportion of subjects with Asperger's syndrome) and "PDD" (proportion of subjects with PDDNOS) were significant for explaining some of the heterogeneity across studies. Studies that included higher proportions of subjects with Asperger's syndrome reported lower prevalence rates of anxiety in general. However, studies that included higher proportions of subjects with PDD-NOS were associated with higher prevalence rates of anxiety in general. Furthermore, for all anxiety subtypes, at least one ASD subtype moderator ("AD," "AS," and/or "PDD") was found significant. Studies that included higher proportions of subjects with autistic disorder were associated with higher prevalence rates of specific phobia and obsessive-compulsive disorder, and lower prevalence rates of generalized anxiety disorder. Studies that included higher proportions of subjects with Asperger's syndrome were associated with higher prevalence rates of generalized anxiety disorder and lower prevalence rates of specific phobia, obsessive-compulsive disorder, social anxiety disorder, and separation anxiety disorder. Finally, studies that included higher proportions of subjects with PDDNOS were associated with lower prevalence rates of obsessive-compulsive disorder, but with higher prevalence rates of specific phobia, generalized anxiety disorder, separation anxiety disorder, and panic disorder. For social anxiety disorder and separation anxiety disorder, the significant effect of the ASD subtype moderators disappeared when multiple moderators were included simultaneously. Also, the moderator "AS" (proportion of subjects with Asperger's syndrome) was no longer found significant in generalized anxiety disorder, when multiple moderators (mean age and method of assessment) were simultaneously included. In the other anxiety subtypes, the effects of the ASD subtype moderators remained significant.

\section{Discussion}

The primary aim of the present study was to estimate the prevalence of (specific) anxiety disorders in children and adolescents with ASD. The secondary aim was to evaluate whether the observed variability in these rates were the result of ASD subtype, age, IQ, and method of assessment (interview versus questionnaire). We now discuss the results of the meta-analysis and the moderator effects and address the limitations and implications of the study.

\section{Prevalence of Anxiety Disorders in Children with ASD}

The results reveal substantial comorbidity for anxiety in children and adolescents with an autistic spectrum disorder: nearly 40 percent were estimated to have clinically elevated levels of anxiety or at least one anxiety disorder. The rate of anxiety observed here is consistent with previous reviews of the ASD literature (e.g., White et al. 2009). In the present study, specific phobia was most common at nearly $30 \%$, followed by obsessive-compulsive 


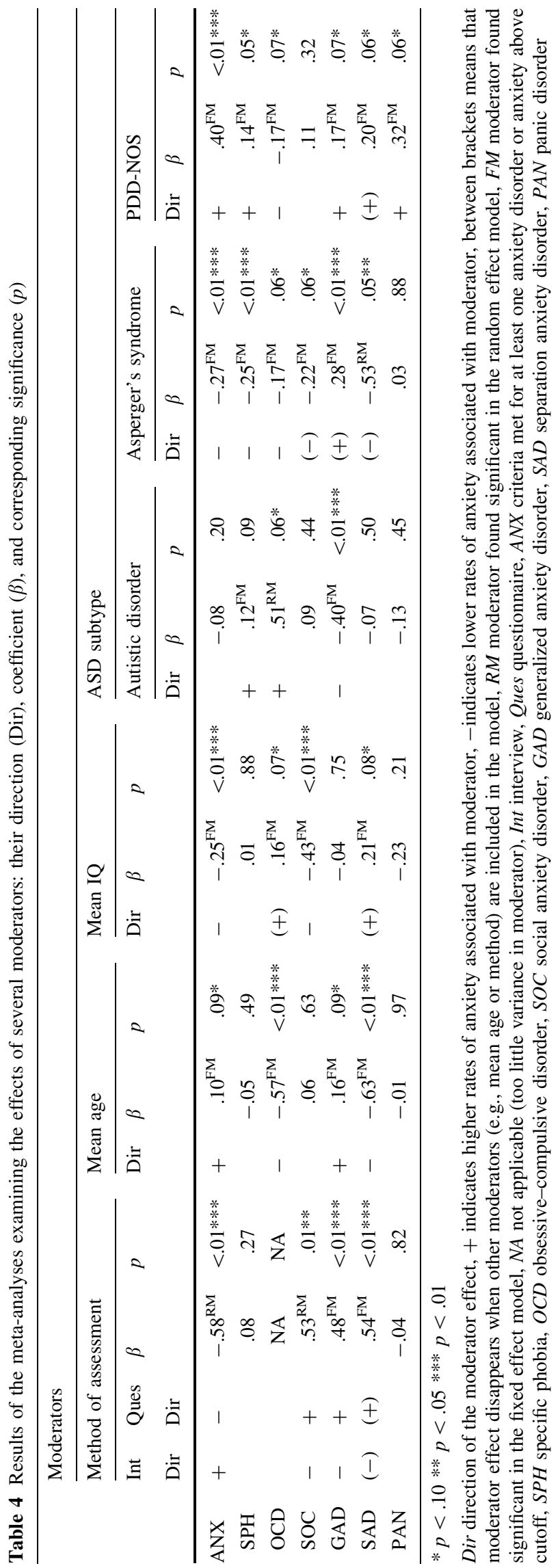

disorder in $17 \%$, social anxiety disorder and agoraphobia in nearly $17 \%$, generalized anxiety disorder in $15 \%$, separation anxiety disorder in nearly $9 \%$, and panic disorder in nearly $2 \%$. By way of comparison, anxiety disorders in typically developing children are estimated to occur in 2.2-27\% (Costello et al. 2005). In addition, with the exception of panic disorder, the rates of the specific anxiety disorders observed in children with an autistic spectrum disorder are more than two times higher than in typically developing children (Costello et al. 2005), and higher than found in children seeking treatment for ADHD (Gau et al. 2010) and learning difficulties (Dekker and Koot 2003).

Evidence of significant comorbidity between anxiety disorders and ASD was found in the current meta-analysis. It is likely that the observed rates of comorbidity between anxiety and ASD arise from diagnostic overlap and the use of measures of anxiety that were never developed for use in ASD populations. However, the studies that used an ASDspecific measurement or made certain adjustments (i.e., excluding particular items) reported prevalence rates of anxiety disorders ranging from $31.5 \%$ to $50.0 \%$, which are in accordance with our estimated prevalence of nearly $40 \%$. A related question that could be raised here is whether the studies measuring anxiety in ASD are really assessing anxiety disorders and not just symptoms of ASD. Clearly, there is diagnostic overlap between the anxiety subtypes and the criteria for ASD, especially between ASD and OCD, and ASD and social anxiety disorder.

It may be that the core symptoms of ASD will be better distinguished from OCD by asking about the target of the interests and routines and comparing it with those of children with OCD. Indeed, Ruta and colleagues (Ruta et al. 2010) found different patterns of symptoms between the children with Asperger's syndrome and children with OCD. In addition, Baron-Cohen and Wheelwright (1999) compared the obsessions of children with ASD and those with Tourette's syndrome. Parents rated the children with ASD to have more obsessions relating to folk physics (e.g., machines, vehicles, computers) or television/audio and displayed fewer obsessions related to folk psychology (e.g., imagination, gossip, beliefs, relationships). Parents of children with Tourette's syndrome reported obsessions relating to sensory phenomena (involuntary touching and vocalizing).

With respect to the discrimination between symptoms of ASD and social anxiety disorder, one discriminating factor may be that the behavioral and non-verbal abnormalities seen in both disorders (e.g., social withdrawal, preference of being alone, and not speaking in social situations, gaze avoidance, staring, and lack of emotional expression) will not be present in every situation and will be strongly influenced by anxiety in individuals with social anxiety disorder, whereas they probably vary less in ASD. Another 
distinctive factor may be that many subjects with social anxiety disorder do have normal social skills and have the ability to use them appropriately in social contexts, whereas subjects with ASD have qualitative impairments in communication and social interaction early in life (APA 2001). Finally, a possible distinction is that the interest in engaging in social situations may be different between the two groups (Bellini 2006), whereas individuals with social anxiety disorder generally have an interest in engaging in social situations, this interest could be less in individuals with ASD.

Likely, such distinctions will not be found when comparing the total score of an anxiety questionnaire to a certain cutoff. Therefore, we need questionnaires that tap the unique and distinct features of anxiety in children with ASD as well as those that are more common to young people with anxiety disorders and no ASD. Likewise, we need measures that do not rely upon parent or child selfreport to give an indication of anxiety, particularly for use with children with more profoundly impaired verbal and communication abilities. Such measures might tap autonomic arousal across baseline and (assumed) anxiety-provoking situations and computerized tests of attentional bias to non-verbal threat cues. Ultimately, it is likely that a combination of questionnaire and interview data, observed behavior/arousal, and multiple informants are required to arrive at a best-guess diagnosis of anxiety disorder in young people with ASD.

\section{Moderators}

\section{Method of Assessment}

Method of assessment was found to influence the wide variability across studies that reported anxiety prevalence rates in children with ASD. Anxiety disorders in general were most likely to be diagnosed where the researchers used interview-based measures rather than questionnaires (mostly parent report version). This may be explained by the goal of the anxiety assessment (diagnosis versus descriptive). If the goal is diagnosis, one may be more likely to use diagnostic interviews; however, if one's goal is descriptive, a questionnaire would be more likely used. For the specific anxiety disorder, generalized anxiety disorder, and social anxiety disorder, however, questionnaires were associated with higher prevalence rates. An important issue here is to distinguish anxiety disorders from anxiety symptoms and to discriminate anxiety symptoms from ASD symptoms. Children with ASD will probably experience many symptoms of social anxiety disorder and generalized anxiety disorder; however, they may not meet criteria for an anxiety disorder because of the lack of interference with their daily activities or because those symptoms are better accounted for by ASD. It is very likely that for this reason studies that used questionnaires to assess (symptoms of) social anxiety disorder and generalized anxiety disorder were found to report higher prevalence rates of those disorders compared with studies that used interviews. This finding suggests that future research will need to employ multi-modal methods for the assessment of anxiety to help disambiguate core ASD symptoms from those of comorbid anxiety disorders.

\section{Mean Age}

In children with ASD, higher rates of anxiety in general were found in studies with a higher mean age. Contradictory results of studies reporting on anxiety in ASD, however, have been found for the relationship between age, anxiety, and ASD. Some studies (Kuusikko et al. 2008; Lecavalier 2006) found older ASD children more likely to report anxiety, while others reported no age differences (Ando and Yoshimura 1979; Pearson et al. 2006; Meyer et al. 2006; Sukhodolsky et al. 2008; White and RobersonNay 2009). It is possible that the type of anxiety disorder under study is an important issue here. For example, we found that studies with a higher mean age also reported higher rates of generalized anxiety disorder and lower rates of separation anxiety disorder. These findings are consistent with the results of studies examining anxiety disorders in typically developing children, which found: (1) rates of anxiety disorders (generally) increase with age (Ford et al.2003); (2) rates of generalized anxiety disorder (specifically) increase with age (Frala et al. 2010; Tracey et al. 1997); and (3) rates of separation anxiety disorder are associated with a lower mean age (Kearney et al. 2003; Last et al. 1992). Interestingly and not consistent with studies that assess anxiety in typically developing children, studies that included younger children with ASD reported higher prevalence rates of obsessive-compulsive disorder than those that included older children with ASD. Obsessive-compulsive disorder in typically developing children, however, tends to have a relatively late age onset (Costello et al. 2005) and is found to increase with age (Ford et al. 2003). However, obsessive-compulsive disorder and the restricted, repetitive behaviors observed in subjects with ASD share much overlap in symptoms and therefore differentiation between the two disorders can be extremely difficult. There is some evidence that younger children with ASD have more restricted, repetitive behaviors compared with older children with ASD (Ebensen et al. 2008) and that children with ASD "improve" in the ritualistic/repetitive behavior domain as they grow older (Piven et al. 1996). These results would seem to support the present finding that a lower mean age in the ASD sample was associated with higher rates of reported obsessive- 
compulsive disorder. However, it is worth noting that (1) in the study of Piven et al. (1996), symptoms in the social and communication domain decreased significantly more over time compared with the symptoms in the ritualistic/repetitive domain; (2) other studies found no association between severity scores of repetitive behavior and age (e.g., South et al. 2005); and (3) some studies found no significant effect of time for the repetitive activities domain (e.g., Starr et al. 2003).

\section{$I Q$}

Across ASD subtypes, increased rates of anxiety disorders in general were associated with lower IQ scores. This finding warrants further investigation as earlier studies point to both positive (Sukhodolsky et al. 2008; Weisbrot et al. 2005; Witwer and Lecavalier 2010) and negative correlations (White and Roberson-Nay 2009) between anxiety and IQ in this population. In post hoc analyses, we found that IQ below versus above 70 did not moderate the relationship between ASD and anxiety disorder, whereas having an IQ below the cross-study mean of 87 did. It is possible that having an IQ between 70 and 87 and ASD increases the risk of anxiety disorders. However, further research is needed as IQ was only significant in the fixed effect model. In addition, the present study found that studies with a higher reported mean IQ were associated with lower rates of social anxiety disorder. However, we note that this finding was significant only in the fixed effect model, and only one study (Sukhodolsky et al. 2008) reported a mean IQ less than 70. Nevertheless, it is possible that children with ASD and a (somewhat) lower IQ have more difficulty adapting to social situations (as compared to those with high IQ who may be more aware of social cues, have learnt how to behave in certain social situations, or may compensate for their deficits). Further, they may notice that they are failing in this domain and therefore become (socially) anxious. In partial support, Kristensen and Torgersen (2008) found that in a population-based screening sample of typically developing children, those diagnosed with social anxiety disorder, as compared to those having other disorders or no disorders, verbal IQ was more reduced. However, whether a lower verbal IQ in typically developing children with social anxiety disorder is also true of children with ASD remains unclear, and the present findings of a relationship between IQ and anxiety in ASD has to be interpreted with caution.

\section{ASD Subtype}

There was some evidence that anxiety in general is more likely to be diagnosed in those with PDD-NOS, followed by those with autistic disorder and Asperger's syndrome.
There was also evidence of certain anxiety disorders being more strongly associated with one or more ASD subtypes. The presence of autistic disorder was associated with higher rates of obsessive-compulsive disorder and specific phobia, but with lower rates of generalized anxiety disorder, while the presence of Asperger's syndrome was associated with lower rates of specific phobia and obsessive-compulsive disorder. Finally, the presence of PDDNOS was associated with higher rates of specific phobia, generalized anxiety disorder, and panic disorder, and with lower rates of obsessive-compulsive disorder.

The few studies that have compared anxiety levels across ASD subtypes suggest that anxiety varies with ASD severity: children with less severe ASD symptoms would endorse more anxiety (MacNeil et al. 2009). A study of Weisbrot and colleagues suggests that children and adolescents with Asperger's syndrome have the highest anxiety levels followed by children with PDD-NOS and autistic disorder, respectively (Weisbrot et al. 2005). However, there are also studies (Kim et al. 2000; Pearson et al. 2006; Gadow et al. 2004; Sukhodolsky et al. 2008) that found no differences in anxiety levels between ASD subtypes. Further, there is some evidence that the kind of anxiety disorders may differ across ASD subtypes; however, results are inconclusive. Muris and colleagues found children with PDD-NOS to be more likely to meet criteria for specific phobia, separation anxiety disorder, and generalized anxiety disorder compared to children with autistic disorder (Muris et al. 1998). In addition, Thede and Coolidge (2007) reported generalized anxiety disorder to be more common in children with Asperger's syndrome as compared to children with high-functioning autism (HFA). It is possible that these associations (found here and elsewhere) are confounded by overlapping phenomenology in ASD and anxiety subtype. An example is the present finding that obsessive-compulsive disorder was higher where a diagnosis of autistic disorder was made and lower in PDDNOS. As subjects with PDD-NOS are less likely to present with severely restricted, repetitive, and stereotyped patterns of behavior (Szatmari et al. 1995; Buitelaar et al. 1999; Starr et al. 2003), the possibility of "misdiagnosis" of obsessive-compulsive disorder in children across the ASD spectrum needs to be considered.

\section{Limitations}

A limitation of the current meta-analytic study was the large heterogeneity found across the meta-analyses. Heterogeneity can arise from a number of factors including methodological differences between studies. An attempt was made to explain this heterogeneity, and we found some significant moderator effects; however, heterogeneity remained significant across all fixed models. One other 
possible moderator that could contribute to the large heterogeneity found in this study, and which we have examined post-analytically, is publication year. We explored this moderator to see whether cohort effects could have biased the results; however, this moderator was not found significant. Further, a warrant is needed as many moderator effects were found significant in the fixed effect models but not in the random effect models. These results should therefore be interpreted with caution as effects found in the fixed effect model only allow for inferences based on the studies included in the meta-analysis and limits the generalizability to other (future) studies (see Hedges and Vevea 1998 for a detailed discussion).

Another limitation to generalization from the present findings was that few studies in the meta-analyses included children with ASD and a low IQ (i.e., below 70). Thus, the rates of anxiety observed here may under- or overestimate the true rate of anxiety in the larger population of children with ASD. There are some tentative findings from the present meta-analyses that suggest that anxiety disorders are more common among those with ASD and a lower IQ, although this relationship varies as a function of ASD and anxiety subtype. Although a significant moderating effect for IQ on rates of anxiety in ASD was only significant in the fixed effect models, the present results suggest that further investigation of this relationship is warranted.

A third limitation is that there were insufficient data to test whether informant moderated the relationship between anxiety and ASD. Until now, researchers have relied heavily on parent reports of anxiety by interviews and questionnaires that were not developed for use with the ASD population. It is widely known that parents tend to underestimate the frequency of internalizing symptoms in their own children (e.g., Muris et al. 1999; Cosi et al.2010) and that child-parent agreement for internalizing problems is generally lower compared with the child-parent agreement of externalizing problems (e.g., Achenbach et al.1987; Cantwell et al. 1997). Future research studies will need to employ multiple informants (where possible) and examine how anxiety varies across informants in terms of frequency, type, and severity.

Finally, large heterogeneity was found for the way anxiety in children with ASD was assessed and whether anxiety was assessed by an instrument developed for or adapted to children with ASD. Inspection of the studies showed that only a few studies used instruments developed for or adapted to children with ASD, and the majority of the studies used instruments developed for typically developing children. Research, however, has not yet established the validity and reliability of those instruments in children with $\mathrm{ASD}$, and therefore conclusions presented here must be seen in this perspective.
Implications

Over the last 30 years, the definition of ASD has broadened and prevalence rates of ASD have risen with estimates of 60 per 10,000 (Fombonne 2003). Although the prevalence of ASD may not be as high as other disorders (such as anxiety or depression), ASD may have incurred significantly higher health service use than other more prevalent disorders. For example, Mandell et al. (2006) found that children with ASD had health care expenditures ten times higher than those without ASD. It seems likely given the high rates of anxiety found in children with ASD that this commonly occurring comorbid problem is a major contributor to health care usage in this population. We know that anxiety disorders in typically developing children significantly interfere with everyday functioning-particularly school attendance (DSM-IV; APA 2001), negatively impact quality of life (Bastiaansen et al. 2004) and are associated with higher health care usage and other social costs (Bodden et al. 2008). It is reasonable to assume that when anxiety disorders occur in young people with ASD, they interact with the ASD such that symptoms of both conditions are exacerbated. In light of the growing demand for evidenced-based treatments (in a context of shrinking health expenditure), it is of major importance to develop better (and more cost-effective) methods for assessing and treating anxiety disorders in children with ASD.

A review of the studies revealed that the assessment of anxiety in children with ASD varies enormously across studies with the majority using instruments that were developed to assess anxiety in typically developing children. The current state of research has not yet examined the validity and reliability of instruments used to assess anxiety in a typically developing population for the ASD population. However, such research is heavily needed. To date, the authors are only aware of one such study. Mazefsky et al. (2011) examined the sensitivity and specificity of self-report questionnaires in adolescents with ASD and compared these self-reports with the outcome of a parental diagnostic interview. Although conclusions are preliminary, the results suggest that such measures may be less sensitive and specific when used in adolescents with ASD than in similarly aged, typically developing adolescents. This may be because children with ASD underreport (anxiety) symptoms (Russell and Sofronoff, 2005). On the other hand, comparing results from self-report measures with parental diagnostic interviews may be problematic as child and parent agreement for anxiety is generally low in typically developing children and the level of agreement may be even less in children with ASD (e.g., children with ASD may lack sufficient insight or emotion language to report accurately on their internalizing symptoms). However, in the study of Mazefsky et al. (2011), it was also found that the results of the internal reliability of 
the self-report questionnaire were as good, or better, than those of the standardization samples and that of all selfreport measures, the RCMAS (Revised Children's Manifest Anxiety Scale; Reynolds and Richmond 1985) showed the most promise (with rather high specificity and positive predictive values). However, efforts are clearly needed to see whether measures of anxiety designed for typically developing children need to be adapted for the ASD populations and/or if alternative norms need to be established.

As discussed earlier, another issue concerning the assessment of anxiety in children with ASD is whether anxiety symptoms can be distinguished from symptoms of ASD reliably. One overall concern may be that measures intended to assess anxiety are merely assessing severity of autism. Although we could not test this concern directly, it is found in this meta-analysis that children with PDD-NOS have higher prevalence rates of anxiety disorders, suggesting that the less severe ASD subtype (as compared to Asperger's syndrome and autistic disorder) would have the highest anxiety scores. This finding is rather contradictory to the concern that assessing anxiety would be the same as assessing severity of ASD. In further support, treatment studies revealed that the symptoms of anxiety, and anxiety disorders, in autism can be decreased (e.g., Sofronoff et al. 2005; Chalfant et al. 2007; Reaven et al. 2009), while the core symptoms of autism are found to be rather persistent (e.g. Billstedt et al. 2007). An examination of the selected studies revealed that only a few studies tried to discriminate between symptoms of ASD and anxiety symptoms and tried to overcome possible confounds by excluding particular items. However, such an approach may also have disadvantages. First, use of anxiety measures adapted for the ASD population will limit comparisons to typically developing children. However, we would argue that it is of clinical value to determine how (if at all) anxiety symptoms and anxiety disorders differ in topography (or impact) in children with ASD compared with typically developing children, and the implication then for etiology and treatment. Regardless of how well we fine-tune the measures, ambiguities may be unavoidable. For example, a positive answer to the question "Do you have difficulty (and avoid) speaking in public?" may never clearly lead one away from ASD to an additional diagnosis of social anxiety disorder. Regardless of whether the additional disorder exists, the difficulty may still warrant intervention if it impairs the child's daily functioning.

It is worth returning to the usefulness of the DSM-IV (APA 2001) in distinguishing anxiety disorders from ASD. The DSM states that social anxiety disorder, generalized anxiety disorder, or separation anxiety disorder should be excluded if the symptoms of these conditions are better accounted for by ASD. Does such a requirement lead to anxiety disorders being under-diagnosed in children with ASD and leave the child less likely to be treated for what are otherwise very treatable conditions in typically developing children? DSM-V (APA 2011) attempts to deal with such issues at least with respect to social anxiety disorder; the proposed changes make an additional diagnosis of social anxiety disorder in children with ASD more easy (Bögels et al. 2010). Similar changes to the criteria for the other anxiety disorders may be needed and would certainly stimulate research in this area (and increase the likelihood of treatment for anxiety in children with ASD). In support of such changes are studies that suggest that anxiety disorders experienced by children with ASD are more similar than different in topography as those experienced by typically developing children with anxiety disorders (Russell and Sofronoff 2005; Farrugia and Hudson, 2006). In addition, as found in this meta-analysis, they appear to follow a similar developmentally sensitive course. We note as well a small but growing body of evidence (e.g., Sofronoff et al. 2005; Chalfant et al. 2007; Reaven et al. 2009) that cognitive behavioral therapy (CBT) as designed to improve anxiety in typically developing children has moderate but positive effects on anxiety disorders in children with ASD. Such findings suggest that greater allowance for the diagnosis of anxiety in ASD in DSM-V is warranted.

Finally, results from the present meta-analyses suggest that children with a particular ASD subtype may be more likely to develop one type of anxiety disorder over another. While the ASD subtypes are more similar than different, the severity of the communication, social interaction, and stereotyped behaviors associated with the subtypes does vary, and this may lead the child more toward one form of anxiety than another. Unfortunately, the severity of each domain of this ASD triad (communication, social interaction, and stereotyped interests and behavior) is rarely reported. Future studies should examine in greater detail whether the rates of particular anxiety disorder vary as a function of the severity of the particular symptoms that make up the ASD subtype. Such an approach would be consistent with changes discussed for the DSM-V wherein ASD subtypes would no longer be distinguished (APA 2011).

Open Access This article is distributed under the terms of the Creative Commons Attribution Noncommercial License which permits any noncommercial use, distribution, and reproduction in any medium, provided the original author(s) and source are credited.

\section{References}

\section{References marked with an asterisk (*) indicate studies included in the meta-analysis.}

Achenbach, T. M. (1991). Manual for the child behavioral checklist/ 4-18 and 1991 profile. Burlington, VT: University of Vermont, Department of Psychiatry. 
Achenbach, T. M., McConaughy, S. H., \& Howell, C. T. (1987). Child/adolescent behavioral and emotional problems: implications of cross-informant correlations for situational specificity. Psychological Bulletin, 101, 213-232.

Ambrosini, P. J. (2000). Historical development and present status of the schedule for affective disorders and schizophrenia for schoolage children (K-SADS). Journal of American Academy of Child Adolescent Psychiatry, 39, 49-58.

Association, American. Psychiatric. (2001). Diagnostic and Statistical Manual of Mental Disorders (DSM-IV-TR). Washington, DC: American Psychiatric Association.

American Psychiatric Association. (2011). Diagnostic and Statistical Manual of Mental Disorders DSM-5 Development proposed revisions anxiety disorders. Retrieved online at January 26th 2011 from: http://www.dsm5.org/ProposedRevisions/Pages/ AnxietyDisorders.aspx.

*Ando, H., \& Yoshimura, I. (1979). Effects of age on communication skill levels and prevalence of maladaptive behaviors in autistic and mentally retarded children. Journal of Autism and Developmental Disorders, 9, 83-93.

Baron-Cohen, S., \& Wheelwright, S. (1999). 'Obsessions' in children with autism or Asperger syndrome. British Journal of Psychiatry, 175, 484-490.

Bastiaansen, A., Koot, H. M., Ferdinand, R. F., \& Verhulst, F. C. (2004). Quality of life in children with psychiatric disorders: Self-, parent- and clinician report. Journal of the American Academy of Child and Adolescent Psychiatry, 43, 221-230.

Begg, C. B., \& Mazumdar, M. (1994). Operating characteristics of a rank correlation test for publication bias. Biometrics, 50, 1088-1101.

Beidel, D. C., Turner, S. M., \& Fink, C. M. (1996). Assessment of Childhood Social Phobia: Construct, Convergent, and Discriminant Validity of the Social Phobia and Anxiety Inventory for Children (SPAI-C). Psychological Assessment, 8, 235-240.

Beidel, D. C., Turner, S. M., \& Morris, T. L. (1998). Social Phobia and anxiety inventory for children (SPAI-C). User's manual, North Tonawanda, NY: Multi-Health Systems Inc.

*Bellini, S. (2004). Social skill deficits and anxiety in highfunctioning adolescents with autism spectrum disorders. Focus on Autism and other Developmental Disabilities, 19(2), 78-86.

Bellini, S. (2006). The development of social anxiety in adolescents with autism spectrum disorders. Focus on Autism and other Developmental Disabilities, 21, 138-145.

Billstedt, E., Gillberg, I. C., \& Gillberg, C. (2007). Autism in adults: symptom patterns and early childhood predictors. Use of the DISCO in a community sample followed from childhood. Journal of Child Psychology and Psychiatry, 48, 1102-1110.

Bodden, D. H. M., Bögels, S. M., \& Muris, P. (2009). The diagnostic utility of the Screen for Child Anxiety Related Emotional Disorders-71(SCARED-71). Behaviour Research and Therapy, 47, 418-425.

Bodden, D. H. M., Dirksen, C. D., Bögels, S. M., Nauta, M. H., de Haan, E., Ringrose, J., et al. (2008). Costs and Cost-Effectiveness of Family CBT versus Individual CBT in Clinically Anxious Children. Clinical Child Psychology and Psychiatry, 13, 543-564.

Bögels, S. M., Alden, L., Beidel, D. C., Clark, L. A., Pine, D. S., Stein, M. B., et al. (2010). Social Anxiety Disorder: Questions and Answers fort he DSM-V. Depression and Anxiety, 27, 168-189.

*Bradley, E. A., Summers, J. A., Wood, H. L., \& Bryson, S. E. (2004). Comparing rates of psychiatric and behavior disorders in adolescents and young adults with severe intellectual disability with and without autism. Journal of Autism and Developmental Disorders, 34, 151-161.

*De Bruin, E. I., Ferdinand, R. F., Meester, S., De Nijs, P. F. A., \& Verheij, F. (2007). High rates of psychiatric co-morbidity in
PDD-NOS. Journal of Autism and Developmental Disorders, 37, 877-886.

Buitelaar, J. K., van der Gaag, R., Klin, A., \& Volkmar, F. (1999). Exploring the boundaries of pervasive developmental disorder not otherwise specified: Analyses of data from the DSM-IV autistic disorder field trial. Journal of Autism and Developmental Disorders, 29, 33-43.

Cantwell, D. P., Lewinsohn, P. M., Rohde, P., \& Selley, J. R. (1997). Correspondence Between Adolescent Report and Parent Report of Psychiatric Diagnostic Data. Journal of the American Academy of Child and Adolescent Psychiatry, 36, 610-619.

Chalfant, A. M., Rapee, R., \& Carroll, L. (2007). Treating anxiety disorders in children with high functioning autism spectrum disorders; a controlled trial. Journal of autism developmental disorders, 37, 1842-1857.

*Chung, S. Y., Luk, S. L., \& Lee, P. W. H. (1990). A follow-up study of infantile autism in Hong Kong. Journal of Autism and Developmental Disorders, 20, 221-232.

Cosi, S., Canals, J., Hernández-Martinez, C., \& Vigil-Colet, A. (2010). Parent-child agreement in SCARED and its relationship to anxiety symptoms. Journal of Anxiety Disorders, 24, 129-133.

Costello, E. J., Egger, H. L., \& Angold, A. (2005). The developmental epidemiology of anxiety disorders: Phenomenology, prevalence, and comorbidity. Child and Adolescent Psychiatric Clinics of North America, 14, 631-648.

*Davis, T. E., Hess, J. A., Moree, B. N., Fodstad, J. C., Dempsey, T., Jenskins, W. S., et al. (2011). Anxiety symptoms across the lifespan in people diagnosed with Autistic Disorder. Research in Autism Spectrum Disorders, 5, 112-118.

Dekker, M. C., \& Koot, H. M. (2003). DSM-IV disorders in children with borderline to moderate intellectual disability. I: Prevalence and impact. Journal of the American Academy of Child and Adolescent Psychiatry, 42, 915-922.

*Demb, H. B., \& Weintraub, A. G. (1989). A five-year follow-up of preschool children diagnosed as having an atypical pervasive developmental disorder. Journal of Developmental and Behavioral Pediatrics, 10, 292-298.

Ebensen, A. J., Seltzer, M. M., Lam, K. S. L., \& Bodfish, J. W. (2008). Age-related differences in restricted repetitive behaviors in autism spectrum disorders. Journal of Autism and Developmental Disorders, 39, 57-66.

Egger, M., Smith, G. D., Schneider, M., \& Minder, C. (1997). Bias in meta-analysis detected by a simple, graphical test. British Medical Journal, 315, 629-634.

Farrugia, S., \& Hudson, J. (2006). Anxiety in adolescents with Asperger Syndrome: Negative thoughts, behavioral problems, and life interference. Focus on Autism and other Developmental Disabilities, 21(1), 25-35.

Fombonne, E. (2003). The Prevalence of Autism. Journal of the American Medical Association, 289, 87-89.

Ford, T., Goodman, R., \& Meltzer, H. (2003). The British Child and Adolescent Mental Health Survey 1999: The Prevalence of DSM-IV Disorders. Journal of American Academic Child and Adolescent Psychiatry, 42, 1203-1211.

Frala, J. L., Leen-Feldner, E. W., Blumenthal, H., \& Baretto, C. C. (2010). Relations among perceived control over anxiety-related events, worry, and generalized anxiety disorder in a sample of adolescents. Journal of Abnormal Child Psychology, 38, 237-247.

*Gadow, K. D., DeVincent, C. J., Pomeroy, J., \& Azizian, A. (2004). Psychiatric symptoms in preschool children with PDD and clinic and comparison samples. Journal of Autism and Developmental Disorders, 34, 379-393.

*Gadow, K. D., DeVincent, C. J., Pomeroy, J., \& Azizian, A. (2005). Comparison of DSM-IV symptoms in elementary school-age 
children with PDD versus clinic and community samples. Autism, 9, 392-415.

Gau, S. S.-F., Ni, H.-C., Shang, C.-Y., Soong, W.-T., Wu, Y.-Y., Lin, L.-Y., et al. (2010). Psychiatric comorbidity among children and adolescents with and without persistent attention-deficit hyperactivity disorder. Australian and New Zealand Journal of Psychiatry, 44, 135-143.

*Gillot, A., Furniss, F., \& Walter, A. (2001). Anxiety in highfunctioning children with autism. Autism, 5, 277-286.

*Green, J., Gilchrist, A., \& Cox, A. (2000). Social and psychiatric functioning in adolescents with Asperger syndrome compared with conduct disorder. Journal of Autism and Developmental Disorders, 30, 279-293.

Hedges, L. V., \& Vevea, J. L. (1998). Fixed- and Random-Effects Models in Meta-Analysis. Psychological Methods, 3, 486-504.

Herguner, S., \& Motavalli, N. (2009). Psychiatric comorbidity in children and adolescents with high functioning autism. European Psychiatry, 24(Supplement 1), 795.

*Kanne, S. M., Abbacchi, A. M., \& Constantino, J. N. (2009). Multiinformant ratings of psychiatric symptom severity in children with autism spectrum disorders: The importance of environmental context. Journal of Autism and Developmental Disorders, $39,856-864$

Kearney, C. A., Sims, K. E., Pursell, C. R., \& Tillotson, C. A. (2003). Separation anxiety disorder in young children: A longitudinal and family analysis. Journal of Clinical Child and Adolescent Psychology, 32, 593-598.

*Kim, J. A., Szatmari, P., Bryson, S. E., Streiner, D. L., \& Wilson, F. J. (2000). The prevalence of anxiety and mood problems among children with Autism and Asperger Syndrome. Autism, 4, 117-132.

Kristensen, H., \& Torgersen, S. (2008). Is social anxiety disorder in childhood associated with developmental deficit/delay? European Child and Adolescent Psychiatry, 17, 99-107.

*Kuusikko, S., Pollock-Wurman, R., Jussila, K., Carter, A. S., Mattila, M. L., Ebeling, H., et al. (2008). Social anxiety in highfunctioning children and adolescents with autism and Asperger syndrome. Journal of Autism and Developmental Disorders, 38, $1697-1709$.

Last, C. G., Perrin, S., Hersen, M., \& Kazdin, A. E. (1992). DSM-III$\mathrm{R}$ anxiety disorders in children: Sociodemographic and clinical characteristics. Journal of the American Academy of Child and Adolescent Psychiatry, 31, 1070-1076.

Lecavalier, L. (2006). Behavioral and emotional problems in young people with pervasive developmental disorders: Relative prevalence, effects of subject characteristics, and empirical classification. Journal of Autism and Developmental Disorders, 36, $1101-1114$.

*Leyfer, O. T., Folstein, S. E., Bacalman, S., Davis, N. O., Dinh, E., Morgan, J., Tager-Flusberg, H., \& Lainhart, J. E. (2006). Comorbid psychiatric disorders in children with autism: Interview development and rates of disorders. Journal of Autism and Developmental Disorders, 36, 849-861.

Lipsey, M. W., \& Wilson, D. B. (2000). In L. Bickman \& D. J. Rog (Eds.), Practical meta-analysis. Oaks: Sage.

*Loggins, K. S., Ivanisevic, M., Robins, D. L., \& King, T. Z. (2010). Anxiety Comorbidity in Children and Adolescents with Autism Spectrum Disorders. The Clinical Neuropsychologist, 24, 557-645.

*Lopata, C., Toomey, J. A., Fox, J. D., Volker, M. A., Chow, S. Y., Thomeer, M. L., et al. (2010). Anxiety and Depression in Children with HFASDs: Symptom Levels and Source Differences. Journal of Abnormal Child Psychology, 38, 765-776.

Lord, C., Risi, S., Lambrecht, L., Cook, E. H., Leventhal, B. L., DiLavore, P. C., et al. (2000). Journal of Autism and Developmental Disorders, 30, 205-223.
Lord, C., Rutter, M., \& Le Couteur, A. (1994). Autism diagnostic interview-Revised: A revised version of a diagnostic interview for caregivers of individuals with possible pervasive developmental disorders. Journal of Autism and Developmental Disorders, 24, 659-685.

MacNeil, B. M., Lopes, V. A., \& Minnes, P. M. (2009). Anxiety in children and adolescents with autism spectrum disorders. Research in Autism Spectrum Disorders, 3, 1-21.

Mandell, D. S., Cao, J., Ittenbach, R., \& Pinto-Martin, J. (2006). Medicaid expenditures for children with autistic spectrum disorders: 1994 to 1999. Journal of Autism and Developmental Disorders, 36, 475-485.

Matson, J. L., Boisjoli, J., \& Wilkins, J. (2007). The Baby and Infant Screen for Children with aUtIsm Traits (BISCUIT). Baton Rouge, LA: Disability Consultants, LLC.

Matson, J. L., \& González, M. L. (2007). Autism Spectrum Disorders-Comorbidity-Child Version. Baton Rouge, LA: Disability Consultants, LLC.

Matson, J. L., \& Nebel-Schwalm, M. S. (2007). Comorbid psychopathology with autism spectrum disorder in children: An overview. Research in Developmental Disabilities, 28, 341-352.

*Mattila, M. L., Hurtig, T., Haapsamo, H., Jussila, K., KuusikkoGauffin, S., Kielinen, M., et al. (2010). Comorbid Psychiatric Disorders associated with Asperger Syndrome/High-functioning Autism: A Community- and Clinic-based study. Journal of Autism and Developmental Disorders, 40, 1080-1093.

*Mazefsky, C. A., Kao, J., \& Oswald, D. P. (2011). Preliminary evidence suggesting caution in the use of psychiatric self-report measures with adolescents with high-functioning autism spectrum disorders. Research in Autism Spectrum Disorders, 5, 164-174.

Mehtar, M., \& Mukaddes, N. M. (2011). Posttraumatic Stress Disorder in individuals with diagnosis of Autistic Spectrum Disorders. Research in Autism Spectrum Disorders, 5, 539-546.

*Melfsen, S., Walitza, S., \& Warnke, A. (2006). The extent of social anxiety in combination with mental disorders. European Child and Adolescent Psychiatry, 15, 111-117.

Meyer, J. A., Mundy, P. C., Van Hecke, A. V., \& Durocher, J. S. (2006). Social attribution processes and comorbid psychiatric symptoms in children with Asperger syndrome. Autism, 10, 383-402.

*Mukaddes, N. M., \& Fateh, R. (2010). High rates of psychiatric comorbidity in individuals with Asperger's disorder. The World Journal of Biological Psychiatry, 11, 486-492.

*Mukaddes, N. M., Hergüner, S., \& Tanidir, C. (2010). Psychiatric disorders in individuals with high-functioning autism and Asperger's disorder: Similarities and differences. The World Journal of Biological Psychiatry, 11, 1-8.

Munafò, M. R., Clark, T. G., \& Flint, J. (2004). Assessing publication bias in genetic association studies: evidence from a recent metaanalysis. Psychiatry Research, 129, 39-44.

Muris, P., Merckelbach, H., Brakel, A., van, \& Mayer, B. (1999). The revised version of the screen for child anxiety related emotional disorders (SCARED-R): Further evidence for its reliability and validity. Anxiety, Stress, and Coping, 12, 411-425.

*Muris, P., Steerneman, P., Merckelbach, H., Holdrinet, I., \& Meesters, C. (1998). Comorbid anxiety symptoms in children with pervasive developmental disorders. Journal of Anxiety Disorders, 12, 387-393.

Nauta, M. H., Scholing, A., Rapee, R. M., Abbott, M., Spence, S. H., \& Waters, A. (2004). A parent-report measure of children's anxiety: psychometric properties and comparison with childreport in a clinic and normal sample. Behaviour Research and Therapy, 42, 813-839.

*Pearson, D. A., Loveland, K. A., Lachar, D., Lane, D. M., Reddoch, S. L., Mansour, R., et al. (2006). A comparison of behavioral and 
emotional functioning in children and adolescents with autistic disorder and PDD-NOS. Child Neuropsychology, 12, 321-333.

*Pfeiffer, B., Kinnealey, M., Reed, C., \& Herzberg, G. (2005). Sensory modulation and affective disorders in children and adolescents with Asperger's disorder. American Journal of Occupational Therapy, 59, 335-345.

Piven, J., Harper, J., Palmer, P., \& Arndt, A. (1996). Course of Behavioral Change in Autism: A Retrospective Study of HighIQ Adolescents and Adults. Journal of the American Academy of Child Adolescent Psychiatry, 35, 523-529.

Reaven, J. A., Blakeley-Smith, A., Nichols, S., Dasari, M., Flanigan, E., \& Hepburn, S. (2009). Cognitive-behavioral group treatment for anxiety symptoms in children with high-functioning autism spectrum disorders: A pilot study. Focus on Autism and Other Developmental Disabilities, 24, 27-37.

Reynolds, C. R., \& Richmond, B. O. (1985). Revised children's manifest anxiety scale manual. Los Angeles: Western Psychological Services.

Rothstein, H. R., Sutton, A. J., \& Borenstein, M. (1996). Publication Bias in Meta-Analysis. Prevention, Assessment and Adjustments. West Sussex, England: Wiley.

Russell, E., \& Sofronoff, K. (2005). Anxiety and social worries in children with Asperger syndrome. Australian and New Zealand Journal of Psychiatry, 39, 633-638.

Ruta, L., Mugno, D., D’Arrigo, V., Vitiello, B., \& Mazzone, L. (2010). Obsessive-compulsive traits in children and adolescents with Asperger syndrome. European Child and Adolescent Psychiatry, 19, 17-24.

Shaffer, D., Fisher, P., Dulcan, M. K., Davies, M., Piacentini, J., Schwab-Stone, M. E., et al. (1996). The NIMH diagnostic interview schedule for children version 2.3. (DISC-2.3): Description, acceptability, prevalence rates, and performance in the MECA study. Journal of the American Academy of Child and Adolescent Psychiatry, 35, 865-877.

*Simonoff, E., Pickles, A., Charman, T., Chandler, S., Loucas, T., \& Baird, G. (2008). Psychiatric disorders in children with autism spectrum disorders: Prevalence, comorbidity, and associated factors in a population-derived sample. Journal of the American Academy of Child and Adolescent Psychiatry, 47(8), 921-929.

Simon, E., \& Bögels, S. M. (2009). Screening for anxiety disorders in children. European Child and Adolescent Psychiatry, 18, $625-634$.

Sofronoff, K., Attwood, T., \& Hinton, S. (2005). A randomised controlled trial of a CBT intervention for anxiety in children with Asperger syndrome. Journal of Child Psychology and Psychiatry, 46, 1152-1160.

South, M., Ozonoff, S., \& McMahon, W. M. (2005). Repetitive behavior profiles in Asperger Syndrome and high-functioning Autism. Journal of Autism and Developmental Disorders, 35, $145-157$.
Spence, S. H. (1997). Structure of Anxiety symptoms among children: A confirmatory factor-analytic study. Journal of Abnormal Psychology, 106, 280-297.

Starr, E., Szatmari, P., Bryson, S., \& Zwaigenbaum, L. (2003). Stability and change among high-functioning children with pervasive developmental disorders: A 2-year outcome study. Journal of Autism and Developmental Disorders, 33, 15-22.

Sterne, J. A. C., Gavaghan, D., \& Egger, M. (2000). Publication and related bias in meta-analysis: Power of statistical tests and prevalence in the literature. Journal of Clinical Epidemiology, 53, 1119-1129.

*Sukhodolsky, D. G., Scahill, L., Gadow, K. D., Arnold, L. E., Aman, M. G., McDougle, C. J., et al. (2008). Parent-rated anxiety symptoms in children with pervasive developmental disorders: Frequency and association with core autism symptoms and cognitive functioning. Journal of Abnormal Child Psychology, 36, 117-128.

Szatmari, P., Archer, L., Fisman, S., Streiner, D. L., \& Wilson, F. (1995). Asperger's syndrome and autism: Differences in behavior, cognition and adaptive functioning. Journal of the American Academy of Child and Adolescent Psychiatry, 34, 1662-1671.

Tabachnick, B. G., \& Fidell, L. S. (2001). Using multivariate statistics. New York: Harper \& Row.

*Thede, L. L., \& Coolidge, F. L. (2007). Psychological and neurobehavioral comparisons of children with Asperger's disorder versus high-functioning autism. Journal of Autism and Developmental Disorders, 37, 847-854.

Tracey, S. A., Chorpita, B. F., Douban, J., \& Barlow, D. H. (1997). Empirical evaluation of DSM-IV generalized anxiety disorder criteria in children and adolescents. Journal of Clinical Child Psychology, 26, 404-414.

Weisbrot, D. M., Gadow, K. D., DeVincent, C. J., \& Pomeroy, J. (2005). The presentation of anxiety in children with pervasive developmental disorders. Journal of Child and Adolescent Psychopharmacology, 15, 477-496.

White, S. W., Oswald, D., Ollendick, T., \& Scahill, L. (2009) Anxiety in children and adolescents with autism spectrum disorders. Clinical Psychology Review, 29, 216-229.

*White, S. W., \& Roberson-Nay, R. (2009). Anxiety, social deficits, and loneliness in youth with autism spectrum disorders. Journal of Autism and Developmental Disorders, 39, 1006-1013.

*Witwer, A. N., \& Lecavalier, L. (2010). Validity of Comorbid Psychiatric Disorders in Youngsters with Autism Spectrum Disorders. Journal of Developmental and Physical Disabilities, $22,367-380$.

*Wozniak, J., Biederman, J., Faraone, S. V., Frazier, J., Kim, J., Millstein, R., et al. (1997). Mania in children with pervasive developmental disorder revisited. American Academy of Child and Adolescent Psychiatry, 36, 1552-1560. 